Original Research Paper

\title{
WeRoute: Route Optimization Web-Based System and Driver Mobile Application
}

\author{
Ang Pei Ying ${ }^{1}$, Justtina Anantha Jothi ${ }^{1}$, Nursakirah ARM ${ }^{1 *}$ \\ ${ }^{1}$ Department of Computing, UOW Malaysia KDU Penang University College. Pulau \\ Pinang, Malaysia.
}

Article History

Received:

08.11 .2021

Revised:

19.12.2021

Accepted:

23.12.2021

*Corresponding Author:

Nursakirah ARM

Email

nursakirah.rm@kdupg.edu.my

This is an open access article, licensed under: $\mathrm{CC}-\mathrm{BY}-\mathrm{SA}$

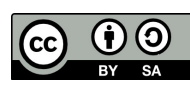

Abstract: This paper intends to conceptualise an optimisation solution for vehicle routing that can get the best routing result and release the most optimal route to the driver, namely WeRoute. The objectives of the paper are to manage the data efficiently, save time, reduce cost, enhance customer satisfaction, and decrease the emission of carbon. Moreover, this is also known as the vehicle routing problem, which deals with a range of variables, including drivers, stops, roads, and customers. The method, Genetic algorithm, was developed to improve the efficiency of generating feasible routes for a project. A team of drivers and several stops are needed to generate the solution of optimising the vehicle routing. It can be said that the more drivers or stops, the more complicated the problem becomes, such as cost controls and vehicle limitations. Thus, a route optimisation tool slowly becomes the key to ensuring the delivery business as efficiently as possible.

Keywords: Genetic Algorithm, Route Optimisation, Vehicle Routing Problem, Web-Based System. 


\section{Introduction}

Route optimising is the process of determining the shortest possible and the most cost-efficient routes to reach a destination. The routing problem is a complex combinatorial optimisation problem that can describe as many requests as possible by the customers, multiple vehicles with constant capacity, and find a route plan for all the vehicles with the lowest travel cost [1]. It is commonly known as the travelling salesman problem (TSP). TSP was studied in the 18th century by William Rowam Hamilton and Thomas Penyngton Kirkman [2]. It is defined as finding the best possible way to visit all the cities and return to the starting point that minimises the travel cost or distance [3]. Thus, WeRoute is a software to solve the problems of designing or planning optimal routes from multiples stops with various constraints, such as cost controls and vehicle limitations. Due to the increased availability of road network data, the efficient processing of generating the most effective route has attracted considerable interest from both research and businesses.

Human nature involves movement from one place to another which increases traffic on the movement route; the increased traffic eventually leads to congestion [4]. Congestion brings a ton of inconveniences and troubles such as delays, high travel costs and environmental pollution. The world's worst congestion in history was located at China National Highway in 2010. The congestion lasted for ten days, and it was 100 kilometres long [5]. This has strongly proved that traditional logistics operation brings a lot of drawbacks and disadvantages. For instance, if a driver was trying to deliver a refrigerator full of food, the client requested to keep the food fresh during the entire delivery process. With the use of traditional logistics method, it requires a long delivery process which causes high emissions of gases that bring adverse effects to the Earth as the operation of refrigeration equipment produces a large amount of carbon dioxide and other greenhouse gases [6]. Moreover, the Malaysian Department of Environment reported that Malaysia carbon dioxide emissions are mainly caused by transportation activities, approximately $97 \%$.

In recent years, the significance of optimising the route of the distribution vehicles has been underpinned due to urban transportation growth [7]. Logistics distribution plays an essential role in goods delivery or transportation due to the market needs. For example, statistics stated that online shopping will make up approximately $22 \%$ of global retail sales by 2023 [8]. The growing number of e-commerce is one of contributing factors to logistics distribution, especially grocery e-commerce. Figure 1 shows the profound change in grocery-related e-commerce over these few years. Therefore, the route of the distribution vehicles and the schedule planning are critical operation decisions [7].

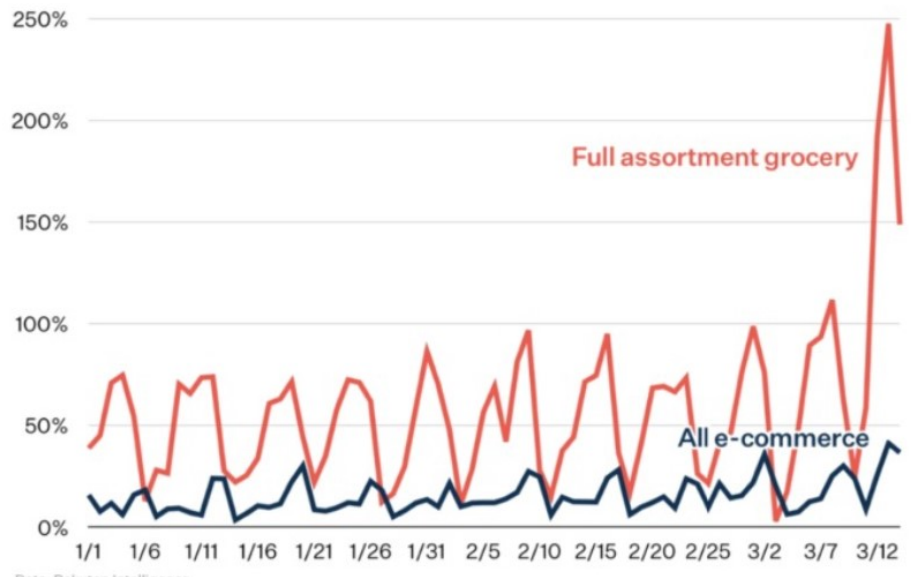

Figure 1. Ecommerce Trending Graph from Rakutan Intelligence [9]

The issue of route planning is very paramount in any organisation, especially such an organisation that provides delivery services. Therefore, this study intends to conceptualise the optimisation solution to aid in route planning which most companies are still doing it manually. It can also be defined as a logistical problem since the advent of widespread delivery such as food and parcel 
delivery. Thus, knowing the issue of route planning can be helpful, which can help businesses to gain confidence by operating their business as efficiently as possible.

\section{Literature Review}

\subsection{Vehicle Routing Problem}

Vehicle Routing Problem (VRP) can be classified as creating taxonomy or creating a generalised framework that summarises the existing models, the objective pursued, and the theories associated with the analysis of the problem. VRP is also defined as a series of delivery points and receiving points, selecting the proper route with certain constraints orderly through them [10]. Many researchers initiated the mathematical encoding formula that involves various complicated algorithms to solve the delivery problems that today's world faces.

Today the world population is nearly 7 billion people and is expected to reach 9 billion by 2040 [11]. It will cause an increase in the use of the requested resources and needs such as water, food, and energy. Thus, the movement of goods is an essential part of economic life as the world faces a drastic change of transportation. The main transport trends are electrification, autonomy, connectivity, and sharing [12]. These four trends will shape the future of commercial urban transport, which will significantly help solve the problem of vehicle routing.

To date, with the integration of the logistics industry, information technology and the trend of globalisation, the whole logistics distribution occupies more and more important status in the system [13]. Also, the transportation system is one of the most critical subsystems in the distribution system, which accounts for approximately $50 \%$ of the total logistics cost. The main objective is to reduce the cost spent and enhance the speed where customer satisfaction, demand, service quality is all met. Thus, this section focuses on the capacitated VRP and its variations.

\subsection{Vehicle Routing Problem and Genetic Algorithm}

Vehicle Routing Problem (VRP) can be defined as a problem of finding the optimal routes of delivery or collection from one or several depots to several customers or cities [14]. It can also be described to find a set of routes with an overall minimum route cosy that service all the demands [15]. Dantzig and Ramser first introduced VRP in 1959, and thousands of research have been done on various VRP variants [14]. For instance, Vehicle Routing Problem with Pick-Up and Delivery (VRPPD), Capacitated Vehicle Routing Problem (CVRP), and Vehicle Routing Problem with Time Windows (VRPTW).

In recent years, the optimisation of logistics distribution routes has attracted extensive attention due to the improvement of people's living standards and their increasing demand for delivery, and it also causes a rapid development in the delivery industry. To exemplify, Datuk Seri Mustapa Mohamed said that Malaysia's online food delivery service market is expected to grow $17.9 \%$ annually to reach a revenue of 370 million USD in four years [16]. Three types of approach have been proposed to solve VRP: exact, heuristics, and hybrid.

In VRP, the routing process is operated by considering the vehicle capacities to ensure that each customer on the routing plan is visited only once [17]. The depot, vehicle, and goods concept can be re-adapted as any logistic or delivery industry, such as the problems of how many stocks are available in the warehouses, how many drivers are available, and how many goods are to be delivered. Moreover, VRP is an NP-Hard type of problem and has been studied for more than fifty years [17], and Genetic Algorithm (GA) is one of the meta-heuristics that developed to solve the problem. Other than GA, several meta-heuristic methods have been successfully applied to solve VRP, such as tabu search and ant colony optimisation.

Several limitations should be taken into consideration while implementing the algorithms to generate solutions for VRP:

- each vehicle travels only one route

- each customer is visited only once

- the load must not exceed the vehicle's capacity

- total distance of the route is minimal, and the starting

- ending point must be at the central distribution, such as warehouse

Furthermore, the process of using GA to achieve a desired result in the project requires several steps. GA is based on Genetics and Natural Selection principles, which includes the initial population, 
fitness function, selection, crossover, and mutation. The process keeps going on if the evaluation criteria are not met [18]. The following Table 1 provides a brief description of GA principles.

Table 1. GA Principles

\begin{tabular}{ll}
\hline \multicolumn{1}{c}{ GA Principles } & \multicolumn{1}{c}{ Descriptions } \\
\hline Initial Population & $\begin{array}{l}\text { A set of individuals, known as population. An individual is also called a } \\
\text { gene; a string of genes is called a chromosome. }\end{array}$ \\
Fitness Function & $\begin{array}{l}\text { Function to compare the ability of everyone and selected the best for } \\
\text { reproduction based on its fitness score. } \\
\text { Two pairs of individuals, parents are selected after going through fitness } \\
\text { function to pass their genes to the next generation. }\end{array}$ \\
Crossover & $\begin{array}{l}\text { A crossover point is chosen at random within the genes from the parents } \\
\text { to produce a new offspring. } \\
\text { After forming a new offspring, a mutation might occur at a low random } \\
\text { probability to prevent premature convergence and maintain the diversity } \\
\text { within the population. }\end{array}$ \\
\hline
\end{tabular}

The procedure for GA to solve the VRP problem is shown in Figure 2. Firstly, the initial population chromosome is generated. A chromosome is represented as a feasible or infeasible path to reach the goal location. After that, a pair of individuals, known as parents with the highest fitness, are selected from the population. In this case, the fitness function is to calculate the shortest distance between each stop, genes. A new route, the chromosome, is created from the parents. Furthermore, the mutation is carried to swap between two stops, whereas crossover ensures the high quality of gene patterns so that a high-quality route can be inherited to the next generation. The process will keep looping until the best route is generated.

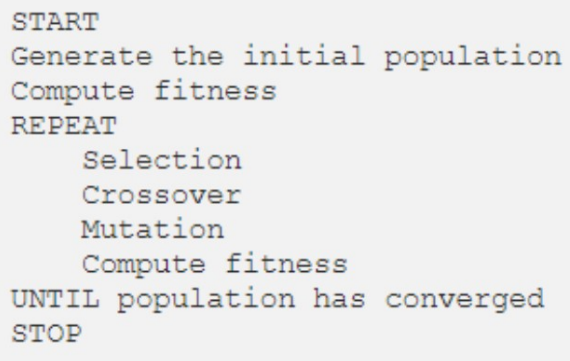

Figure 2. Pseudocode of Genetic Algorithm [19]

Delivery companies often organise a hub delivery network, as flows between hubs are characterised by economies of scale [20]. Companies such as POS Malaysia will have indicated significant reductions in unit transportation costs with increasing vehicles that operate between hubs. The cost functions that include the concept of economies of scale are non-linear. Thus, the economies of scale provide the rationale to use GA while solving the parcel express service delivery problem [20]. An example of implementing GA in the delivery companies will be shown as follows:

- Initial Population: 25

- Number of drivers assigned: 3

- Maximum number of orders received per driver: 10

- Maximum distance travelled by each driver: 200 kilometres 
- Crossover rate: 0.7

- Mutation probability: 0.3 .

The example of the result is shown in Table 2, where GA is implemented to fulfil the requirements. The process keeps going on when the population does not meet the evaluation criteria.

Table 2. Example Result of Route Optimisation

\begin{tabular}{cclcc}
\hline Drivers & $\begin{array}{c}\text { Number of } \\
\text { Orders }\end{array}$ & \multicolumn{1}{c}{ Optimal Routes } & $\begin{array}{c}\text { Total } \\
\text { Distances } \\
(\mathbf{k m})\end{array}$ & $\begin{array}{c}\text { Efficiency } \\
\text { Rate }\end{array}$ \\
\hline 1 & 9 & A-C-B-I-H-D-E-G-F & 198.54 & 0.29 \\
2 & 7 & F-C-G-A-D-B-E & 167.88 & 0.25 \\
3 & 9 & G-E-A-F-H-I-B-C-D & 188.98 & 0.31 \\
\hline
\end{tabular}

Many experts and scholars achieved excellent achievements in the VRP issue in the past decades; researcher concludes that a VRP problem has various solutions where different algorithms will lead to different results. The reasons why GA is selected for this project are its simplicity and flexibility, it supports multiple objectives optimisation, and it works well in complicated environments as it is one of the pioneer evolutionary algorithms. Thus, each VRP problem needs to be solved with its best rule to achieve solving and get the most effective result.

\section{Proposed Work}

WeRoute is a web-based route optimisation and management system which aims to manage drivers and stops and at the same time optimise routes based on the project and a driver mobile application where the driver receives all the active routes that are successfully assigned to them. The advantage of this system is that it helps in minimising human dependency as a human cannot efficiently compute all the different parameters to find an optimal route, especially in a short amount of time. WeRoute helps to solve the difficulties of calculating and finding the best way for each driver. It needs to save all the drivers and stops in advance and create a project for route optimisation.

Moreover, WeRoute quickly is dispatched to all the drivers with just a button. The dispatch button is to generate the most effective route for every driver by using GA. For instance, three drivers and 30 stops are loaded in the system; each driver will be assigned a route that takes the shortest distance. Thus, the driver can receive instructions for a particular project and collect a customer's signature as proof of delivery. Another functionality is that the administrator can track the delivery process status via the driver mobile application. For example, if one of the drivers gets delayed, the admin can see it from the tracking page. Thus, the administrator can update their drivers to start the delivery as soon as possible. This will also help in customer service as well as improving the accountability of the drivers. Nonetheless, the administrator can download the project in an excel format after optimising and dispatching. This can ease the workload of the administrator to check for the project's details.

The most important part of the entire system is optimised, as its main purpose is. It uses a genetic algorithm to optimise the route and can be dispatched to the drivers. Dispatching to the driver is also one of the essential functionalities as the driver is the one who delivers the goods. The integration between the web management system and mobile application is the key to make dispatching successful. Figure 3 show the flow chart, and Figure 4 to Figure 9 illustrates the user interface of webbased route optimisation and management system.

When a project is selected, all the drivers and stops for that particular project will be displayed on the map, as shown in Figure 4. There are examples of infoboxes for driver and stop, shown in Figure 5 when the icons are clicked. All the essential information is displayed in the infobox, such as stop name or driver name.

Once the project is successfully optimised and dispatched, the user can track and download the project, as shown in Figures 8 and 9. 


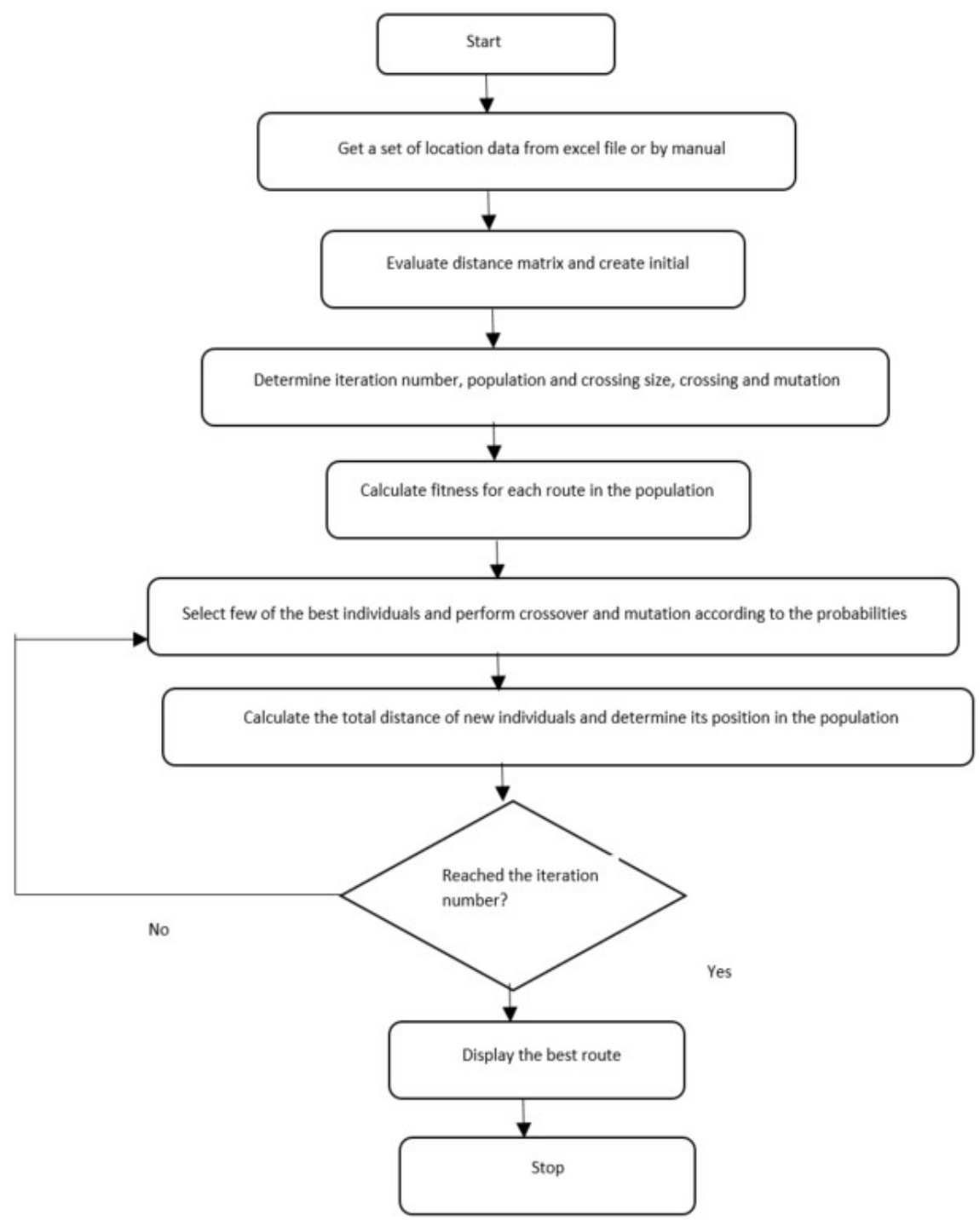

Figure 3. Flowchart on Best Route Generation via GA

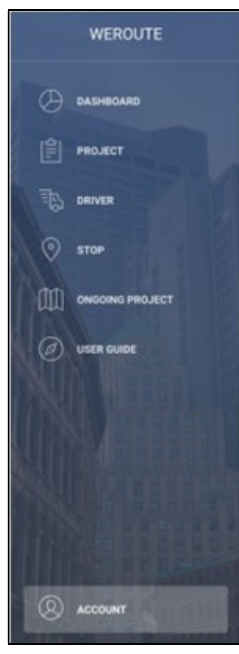

Dashboard

Welcome to WeRoute

sonesontar unes

iE adidersiect

- idodiver

- andana

sour wros or voun ncocour

Anount of Project: 0

Amount of Active Project o

Amount of Dispatched Project: 0

Amount of Driver: 0

Amount of Diver 0
Amount of Stop : 0

Figure 4. WeRoute Dashboard 


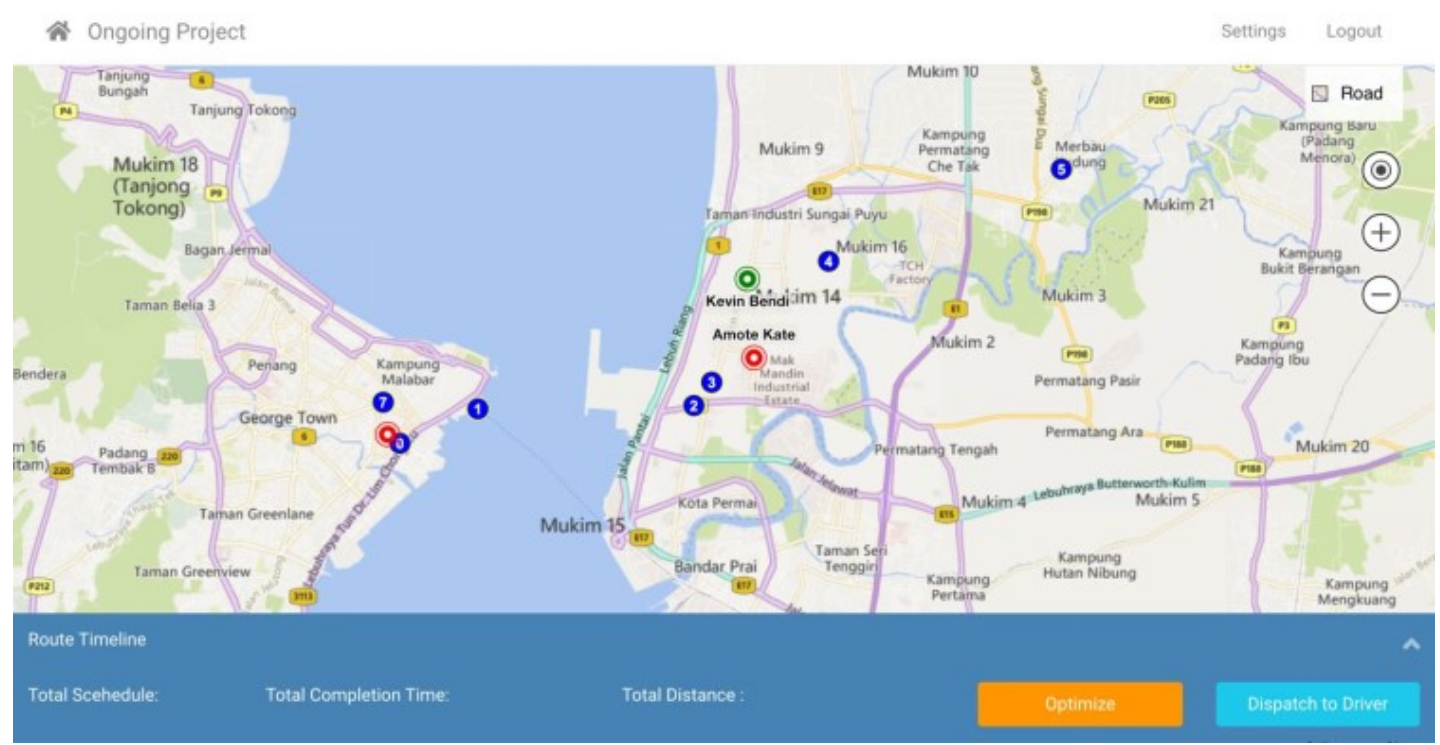

Figure 5. WeRoute Ongoing Project

Figure 6 shows an interface when the project has not been started or delivered and a tracking status update when the driver has updated the status through the driver mobile application.

^ Ongoing Project

Settings Logout

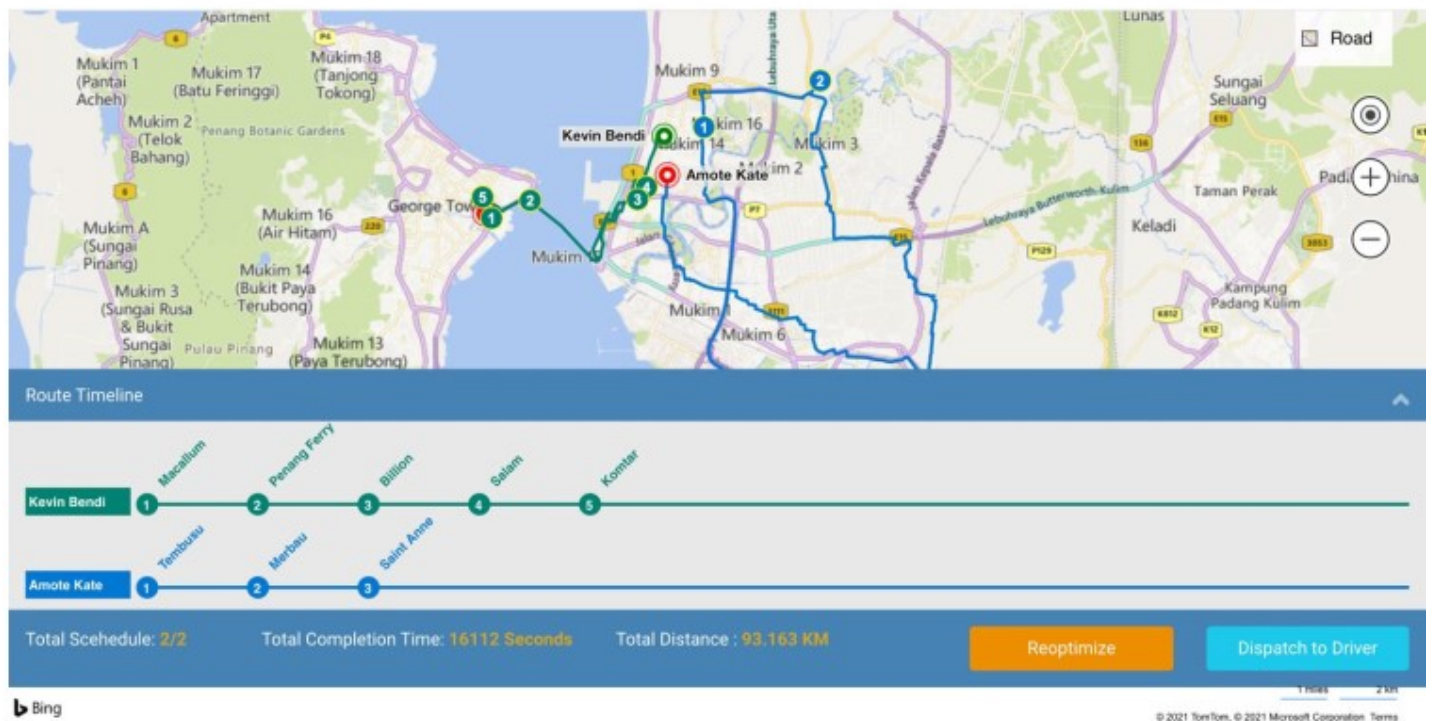

Figure 6. Ongoing Project, Optimised Success, and Route Timeline 

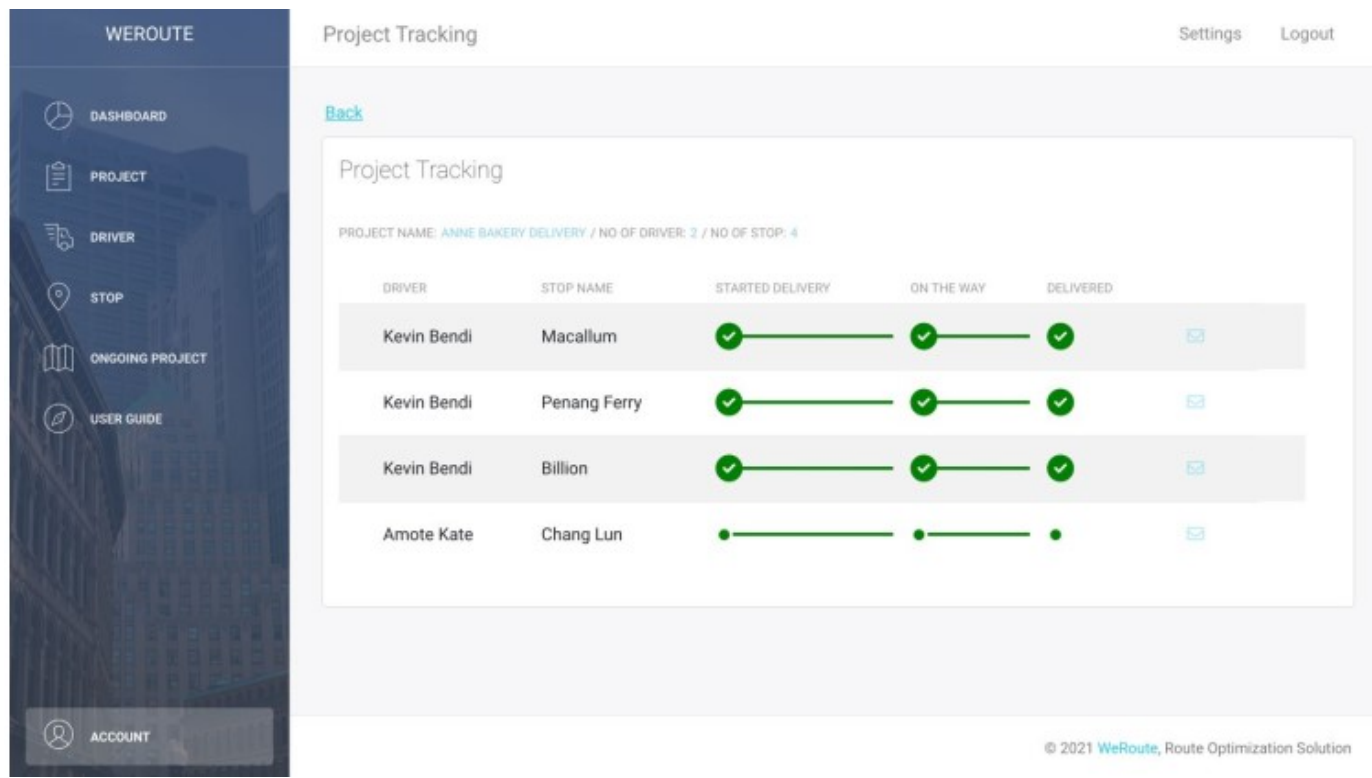

Figure 7. Project Tracking, Status Updated Example

DOWNLOAD OPTIMIZED \& DISPATCHED PROJECT:

\# $\quad$ PROJECT NAME

1 Fishy Fushy

Download

2 Desato Cupcake Delivery

Download

Figure 8. Dashboard, Downloadable Optimised and Dispatched Project

Moreover, to download the optimised and dispatched project, the user has to go to the dashboard page, and the table will be updated with the project information, as shown in Figures 8 and 9.

\begin{tabular}{|c|c|c|c|c|c|c|c|c|c|c|}
\hline 1 Project Name: & \multicolumn{2}{|c|}{ Desato Cupcake Delivery } & \multirow[b]{2}{*}{ Stop Address } & \multirow[b]{2}{*}{ Stop Latitude } & \multirow[b]{2}{*}{ Stop Longitud } & \multirow[b]{2}{*}{ Stop/Customer Phone } & \multirow{3}{*}{$\begin{array}{l}\text { Stop/Customer Email } \\
\text { MACA@GMNL.COM }\end{array}$} & \multirow{3}{*}{ Stop Note 1} & \multirow{3}{*}{ Stop Note 2} & \\
\hline 2 Driver Name & Driver Phone & Stop Name & & & & & & & & \\
\hline 3 KEVNBENDI & 760123456789 & Macillum & GATLEBUH MACALLUM GEORGE TOV & V $\quad 5.4081$ & 100.3317 & "60192223339 & & & & \\
\hline 4 KEVNBENOI & 760123456789 & PENANG FERRY & GEORGETOWN, 10300 GEORGE TOWI & 5.413507 & 100.343622 & & & LATEDELIVERT & IS ACCEPTABLE & E, DONT HURRY \\
\hline 5 KEVNBENDI & 760123456789 & BLLLON & BILION SHOPPING CENTRE, KAMPUN & 5.414041 & 100.376985 & & & & & \\
\hline 6 KEVN BENOI & 760123456789 & SALAM & KAMPUNG PAYA 12300 BUTTERWOR & 5.417651 & 100.379699 & & & & & \\
\hline 7 KEUNBENOI & 760123456789 & KOMTAR & KOMTAR, GEORGE TOWN, PENANG,N & 5.4145 & 100.329 & & KOMTAR@KKK.COM & & & \\
\hline 8 AMOTE KATE & 760192223334 & TEMBUSU & 1212-1216, JALAN TEMBUSU, KAMPC & 5.436242 & 100.397674 & & & & & \\
\hline 9 aMotekate & 760192223334 & MERBAU & IALAN MERBAU KUDUNG, 13800 TASI & 5.450352 & 100.433532 & & & & & \\
\hline 10 AMOTE KATE & 760192223334 & SAINT ANNE & 14000 BUKIT MERTANAM, PENANG & 5.351314 & 100.477744 & & SAINT@GGG.COM & & & \\
\hline 11 & & & & & & & & & & \\
\hline 12 & & & & & & & & & & \\
\hline 13 & & & & & & & & & & \\
\hline
\end{tabular}

Figure 9. Example of Downloaded Project Report 


\section{Conclusion}

WeRoute is a software that helps increase delivery's productivity by saving cost, enhancing customer satisfaction, and reducing the emission of carbon. It eases the tasks of the administrator and driver. It aims to create more additional valuable features to make the entire delivery process even more accessible. The developer believes that technology is changing the business landscape as today business world is often hit especially hard by technology changes because they can result in the complete renovation of a process or even an entire industry.

A simple procedure for the web application is that the administrator first creates a project and adds drivers and stops in each section. After that, he is responsible for looking for the desired drivers and stops for each project and updating them to the project. Everything is good to go by optimising and dispatching. For mobile applications, the driver receives the project once it is dispatched. The driver is responsible for delivering with start and end buttons and collecting signatures from the customers.

In addition, one of the recommendations for the project is to make some improvements to the algorithm. A better result requires effort to study the real-time traffic data to calculate the time taken for a specific route in a specific time. Moreover, balancing stop distribution is also one of the recommendations as the system now optimises without balancing the number of stops for the driver. For instance, there are five drivers and 50 stops. Balancing means distributing a balanced amount of routes to these five drivers so each driver will have ten stops. Another recommendation to improve the project is to collaborate with other developers to figure out the best outcome as group work makes a higher quality solution than individuals. The developer believes that the project will increase its usability, functionality, and security if it collaborates.

The recommendation to improve the mobile application is to have a more user-friendly and beautiful interface design as the current interface is simple but not good in looking. An update in the user interface will undoubtedly provide greater convenience to the driver and make the mobile application felt seamless and intuitive. They were also creating more functionalities such as leaving messages to the customer before arrival, uploading a profile picture to let the customer recognise whom to approach, and merging the mobile application with Bing Maps so that the driver does not need to use other navigation services to reach the destination. These are the recommendations to make the application much better in the future.

\section{References}

[1] A. Király and J. Abonyi, "Optimization of Multiple Traveling Salesmen Problem by a Novel Representation based Genetic Algorithm," in Intelligent Computational Optimization in Engineering, pp. 241-269. Berlin, Heidelberg: Springer, 2011.

[2] J. Matai, S. P. Singh, and M. L. Mittal. "Traveling Salesman Problem: An Overview of Applications, Formulations, and Solution Approaches," Traveling Salesman Problem, Theory and Applications, vol. 1, 2010.

[3] I. Y. Panessai, M. M. Lakulu, MS. K. Subramaniam, A. Alias, H. F. Hanafi, and H. Naparin, "Increasing the Performance of Genetic Algorithm by Using Different Selection: Vehicle Routing Problem Cases," in Proceedings of the World Congress on Engineering and Computer Science, San Francisco (USA), October 23-25, 2018.

[4] D. L. T. Bale, C. Ugwu, and E. O. Nwachukwu, "Route Optimization Techniques: an Overview," International Journal of Scientific \& Engineering Research, vol. 7, no. 11, pp. 1367-1372, 2016.

[5] C. Custer, "China's Traffic Troubles. [Online] Available: https://www.thoughtco.com/chinastraffic-troubles-687418. [Acessed: 2021].

[6] J. Chen, P. Gui, T. Ding, S. Na, and Y. Zhou, "Optimisation of Transportation Routing Problem for Fresh Food by Improved Ant Colony Algorithm based on Tabu Search," Sustainability (Switzerland), vol. 11, no. 23, 2019. doi: 10.3390/su11236584.

[7] Armstrong, J. Andrew, S. Halabi, J. Luo, D. M. Nanus, P. Giannakakou, R. Z. Szmulewitz, D. C. Danila, "Prospective Multicenter Validation of Androgen Receptor Splice Variant 7 and Hormone Therapy Resistance in High-Risk Castration-Resistant Prostate Cancer: the Prophecy Study," Journal of Clinical Oncology, vol. 37, no. 13 pp. 11-20, 2019.

[8] B. Estay, "16 Online Shopping Statistics: How Many People Shop Online?," [Online] Available: https://www.bigcommerce.com/blog/online-shopping-statistics/\#get-to-know-thecustomers-who-shop-online. [Acessed: 2021]. 
[9] A. Orendorff, "10 Ecommerce Trends for 2021: Growth Strategies, Data \& 17 Experts on the Future of Direct-to-Consumer (DTC) Retail. [Online]. Available: https://commonthreadco. com/blogs/coachs-corner/ecommerce-trends-future. [Acessed: 2021].

[10] Bale, W. Christopher, E. Bélisle, P. Chartrand, S. A. Decterov, G. Eriksson, A. E. Gheribi, K. Hack, "Reprint of: Fact Sage Thermochemical Software and Databases," Calphad, vol. 55, pp. 1-19, 2016.

[11] O. E. M. Toro, Z. A. H. Escobar and E. M. Granada, "Literature Review on the Vehicle Routing Problem in the Green Transportation Context," Luna Azul, vol. 42, pp. 362-387, 2015. doi: 10.17151/luaz.2016.42.21.

[12] S. Bouton, E. Hannon, L. Haydamous, B. Heid, S. Knupfer, T. Naucler, S. Ramanathan, an Integrated Perspective on the Future of Mobility, Part 2: Transforming Urban Delivery. Chicago: McKinsey \& Company, 2017.

[13] R. Zhu and Y. Zhai. "Research on the application of genetic algorithm in logistics location," in ICCSS 2017 - 2017 International Conference on Information, Cybernetics, and Computational Social Systems, vol. 5064, pp. 435-438, 2017. doi: 10.1109/ICCSS.2017.8091454,.

[14] C. Liong, "Vehicle routing problem: models and solutions," Journal of Quality Measurement and Analysis, vol. 4, no. 1, pp. 205-218, 2008.

[15] I. Y. Panessai, M. S. Baba, and N. Iksan, "Solving Rich Vehicle Routing Problem Using Three Steps Heuristic," International Journal of Artificial Intelligence, vol. 1, no. 1, pp. 1-19, December 2014. doi: 10.36079/lamintang.ijai-0101.9

[16] Bernama. "Online food delivery market to see robust growth over next four years" [Online] Available: https://www.theedgemarkets.com/article/online-food-delivery-market-see-robustgrowth-over-next-four-years. [Acessed: 2021].

[17] I. Yusuf, N. Iksan, and M. S. Baba, "Solving Rich Vehicle Routing Problem Using Three Steps Heuristic," International Journal of Information Science and Intelligent System, vol. 3, no. 1, pp. 53-72, 2014.

[18] I. Yusuf, M. S. Baba, and N. Iksan, "Applied Genetic Algorithm for Solving Rich VRP," Applied Artificial Intelligence, vol. 28, pp. 957-991, 2014. doi: 10.1080/08839514.2014. 927680.

[19] V. Mallawaarachchi, "Introduction to Genetic Algorithms - Including Example Code," 2017. [Online]. Available: https://towardsdatascience.com/introduction-to-genetic-algorithms-includ ing-example-code-e396e98d8bf3. [Acessed: 2021].

[20] A. Cupić and D. Teodorović, "A multi-objective approach to the parcel express service delivery problem," Journal of Advanced Transportation, vol. 48, no. 7. doi: 10.1002/atr. 